\title{
Ovarian teratoma displaying a wide variety of tissue components in a broiler chicken (Gallus Domesticus): morphological heterogeneity of pluripotential germ cell during tumorigenesis
}

\author{
S. Ohfuji* \\ Department of Histopathology, Diagnostic Animal Pathology Office, Hokkaido, Japan
}

\begin{abstract}
Spontaneous ovarian teratoma was found in a seven-week-old female Chunky broiler chicken that was slaughtered for food. On post-mortem inspection, a spherical tumor mass attaching to a juvenile ovary was found in the abdominal cavity. Histopathologically, the tumor was comprised of immature mesenchymal stroma and a variety of mature tissue elements of mesodermal and ectodermal origin. In addition, there were multiple indistinguishable tissue elements, which showed no malignant cytological features but were unidentifiable as to corresponding embryological layer of origin. These heterogeneous teratoma tissues consisted of a variety of glandular, cystic, duct-like, and tubular structures, some of which exhibited a lining by a mixture of both keratinizing/non-keratinizing stratified squamous epithelial cells and cuboidal/columnar epithelial cells. The ovarian tetatoma was considered a benign and congenital one. The highly diverse differentiation of the teratoma might have manifested a morphological aspect of intrinsic character of the pluripotential germ cells during tumorigenesis.
\end{abstract}

Keywords: Chicken, Heterogeneous differentiation, Ovary, Teratoma.

\section{Introduction}

Although uncommon, ovarian teratomas that are classified into a category of the germ cell tumors have been previously described in human beings (Kraus, 1977; Outwater et al., 2001; Kuno et al., 2004; Schanmughapriya et al., 2011), nonhuman primates (Baskin et al., 1982), experimental rats (Tsubota et al., 2004), and domestic animals, including horses, pigs, dogs, and cattle (Dehner et al., 1970; Gruys et al., 1976; Rodríguez et al., 1994; Basaraba et al., 1998; MacLachlan and Kennedy, 2002; Sato et al., 2003; Lefebvre et al., 2005; Schlafer and Miller, 2007; Gamba et al., 2014). Spontaneous ovarian or intraabdominal teratomas have been reported in the avian species, including chickens (Campbell and Appleby, 1966; Helmboldt et al., 1974; Gupta, 1976; Mohamed et al., 2006), ducks (Cullen et al., 1991; Bolte and Burkhardt, 2000), a goose (Reece and Lister, 1993), and a bald eagle (Ford et al., 2006). It appears that ovarian teratomas are rare in broiler chickens possibly due to their young age; a short life span.

Most ovarian teratomas are benign in domestic animals, with the exception of their malignant counterparts that have rarely been reported in the bitch and mare (Gruys et al., 1976; McEntee, 1990). Unlike most of other tumor types, ovarian teratomas certainly differentiate to produce a wide variety of tissue components which are composed of well-differentiated mature tissues, and this phenomenon is explained by the fact that the tumors arise from pluripotential germ cells that have undergone somatic differentiation (Dahl et al., 1990; MacLachlan and Kennedy, 2002; Schlafer and Miller, 2007). Although ovarian teratomas commonly show variable tissue components, the occurrence of heterogeneous components which are difficult to give appropriate anatomical designation may be uncommon in the tumor. Therefore, the purpose of the present study was to describe the histopathological features of a spontaneously occurring benign ovarian teratoma in a broiler chicken, which presented with not only well-differentiated mature tissues of mesodermal and ectodermal origin, but also remarkably diverse differentiation of teratoma components unidentifiable as to corresponding embryological layer of origin.

\section{Materials and Methods}

A flock of seven-week-old Chunky chickens (Gallus domesticus) were slaughtered at an abattoir. These chickens had been managed for meat production by a commercial company where there were no epidemiological or other serious problems. The flock was composed of approximately 150 chickens derived from a similar genetic background. Physical examination prior to slaughter revealed no significant clinical signs in all these chickens. At post-mortem examination, a female broiler chicken exhibited a tumor mass in the abdominal cavity. The remaining chickens from the same flock, which were processed on the same day, were reported by the veterinary meat inspectors to be unaffected with neoplastic lesions in the ovary or other visceral organs. For

*Corresponding Author: Susumu Ohfuji. Department of Histopathology, Diagnostic Animal Pathology Office, Hokkaido, 
histopathological diagnosis of the ovarian tumor, tissue samples were taken immediately after slaughter from the tumor. Additional samples were collected from major visceral organs, including the liver, spleen, kidney, heart, lung, and intestine. These tissue samples were fixed in $10 \%$ formalin. After fixation, a whole ovarian tumor was cut into many portions that were prepared for histopathology. All tissue blocks were embedded in paraffin wax, processed routinely, sectioned at $4 \mu \mathrm{m}$, and stained with hematoxylin and eosin (HE).

\section{Results}

On post-mortem examination, the broiler chicken under study exhibited a spherical tumor mass, approximately $9.0 \mathrm{~cm}$ in diameter (Fig. 1a). The tumor mass was loosely attached to a juvenile ovary. It was soft as a whole, except for some areas gritty to feel on sectioning, and its cut surface showed a mottled gray and tan appearance with occasional cystic areas. Other organs, such as the heart, lung, kidney, spleen, liver, and bowel, were unremarkable.

On histopathology, the tumor was covered by single layer of cuboidal epithelial cells. The tumor comprised a haphazard arrangement of immature mesenchymal stroma and a variety of disorganized, different, somatic tissue elements, enabling a diagnosis of teratoma to be made. Immature mesenchymal cells exhibited round or ellipsoidal pale nuclei with small nucleoli, a small amount of basophilic cytoplasm, and rare mitotic figures ( $<1$ per $200 \mathrm{x}$ field). Many teratoma elements were mature, including extensive areas of the central nervous gray matter, which either contained polygonal neurons and oligodendroglia (Fig. 1b) or had rarely cuboidal-lined small rosettes; large cavities reminiscent of the cerebral ventricles which were lined by a single layer of spherical cells; nerve fiber bundles of the peripheral nervous system (Fig. 1c); varying-sized groups of striated myofibers (Fig. 1d); bone trabeculae accompanied by osteoblasts, multinucleated osteoclasts, and hematopoietic (erythropoietic and leukopoietic) bone marrow (Fig. 1e); scattered islands of hyaline cartilage enclosed with a membrane of many collagen fibers (Fig. 1f); scattered areas of adipose tissue; and a few encapsulated lymphoid follicles.

Other teratoma elements consisted of a variety of aberrant tissue types, which exhibited no characteristics to a sufficiently distinctive degree to allow identification of intrinsic somatic organs or tissues. Apparent malignant features, such as anisokaryosis, anisocytosis, substantial mitotic figures indicative of rapid growth, and metastatic or invasive behavior, were not recognized in these tissue types. Such aberrant teratoma elements included secretory glands with or without duct-like lumens (Figs. 2a and 2b); glandular structures lined by a layer of cuboidal or columnar epithelial cells (Fig. 2c); duct-like structures lined by a single to multilayered pale cuboidal or columnar epithelial cells (Fig. 2d); cystic structures lined by a single layer of squamous epithelial cells, which were surrounded by immature mesenchymal cells and collagen fibers (Fig. 2e); and variably-sized cystic structures similar to epidermoid cysts or feather follicles devoid of feathers, which were lined by keratinizing stratified squamous epithelial cells (Fig. 2f). In addition, the most unique teratoma elements were comprised of a triad of epitheliallined cystic, tubular, and duct-like structures. First, cystic structures were composed of a partial lining by multilayered cuboidal epithelial cells, the other

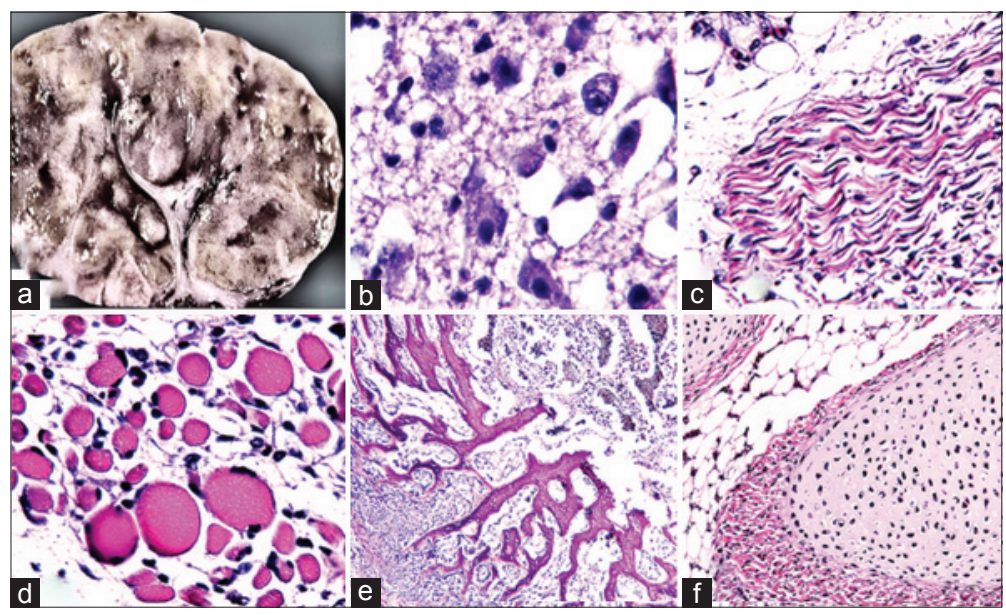

Fig. 1. (a) Teratoma after fixation shows a cavitary appearance on cut section. (b) Polygonal neurons in the neuropil-like area of teratoma (HE x 200). (c) Nerve bundle similar to peripheral nerve (HE x 100). (d) A group of varying sized striated myofibers (HE $\mathrm{x}$ 100). (e) Bone trabeculae accompanied by hematopoietic bone marrow (HE x 100). (f) Insular hyaline cartilage surrounded by a membrane of collagen fibers (HE x 100). 


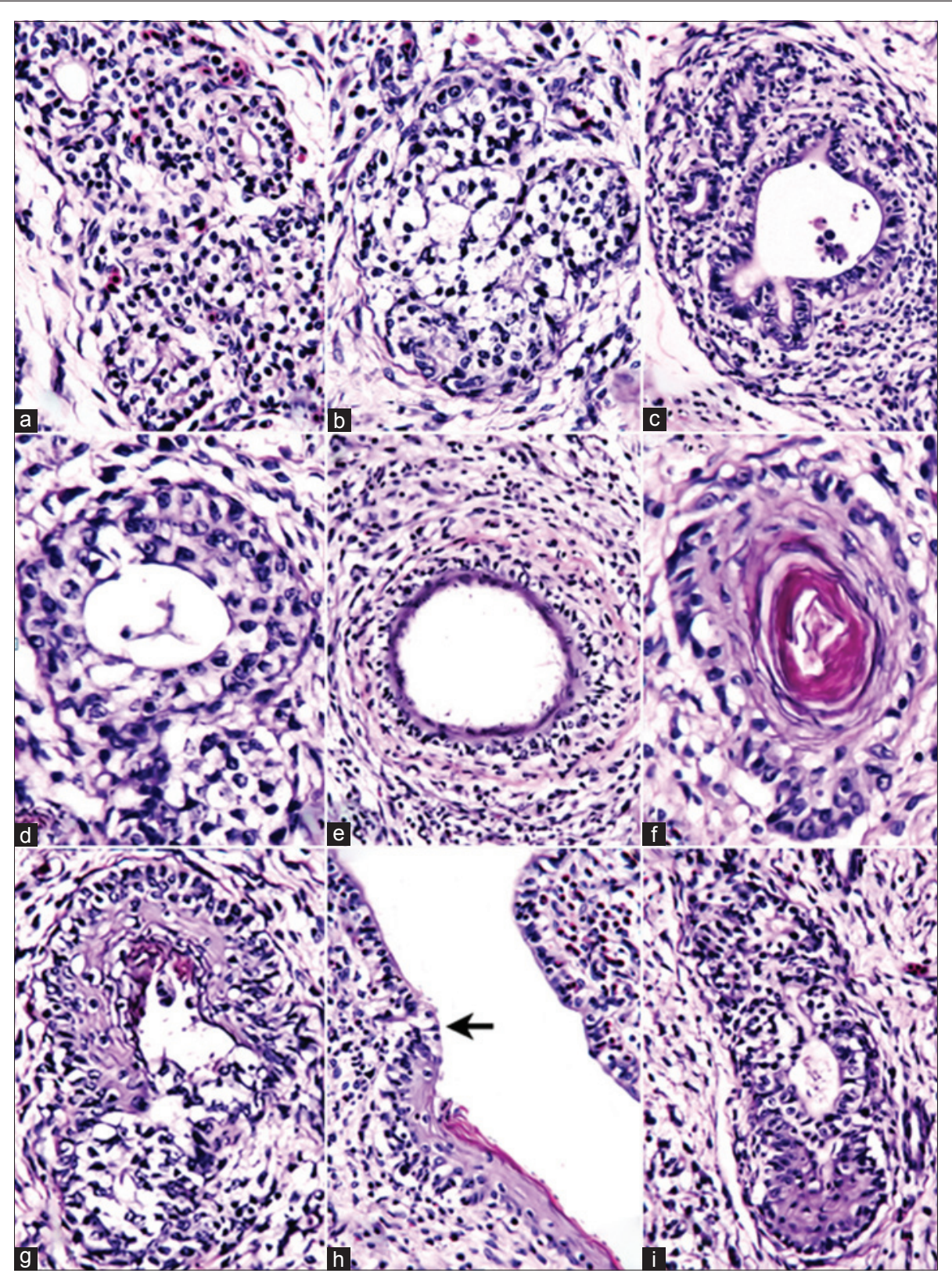

Fig. 2. (a) Teratoma represents secretory gland composed of cuboidal-lined acinar structure which has duct-like lumens (HE x 100). (b) Secretory gland composed of cuboidal-lined acinar structure without ducts (HE x 100). (c) Glandular structure lined by a layer of cuboidal or columnar epithelial cells (HE x 100). (d) Tubular structure lined by a single to multilayered, pale, cuboidal or columnar epithelial cells (HE x 200). (e) Cystic structure lined by a single layer of squamous epithelial cells, which is surrounded by immature mesenchymal cells and collagen fibers (HE x 100). (f) Cystic structure similar to epidermoid cyst or feather follicle lacking feathers which is lined by keratinizing stratified squamous epithelial cells (HE x 200). (g) Cystic structure composed of a partial lining of both multilayered cuboidal epithelial cells and keratinizing stratified squamous epithelial cells (HE x 100). (h) Tubular structure is lined by both columnar epithelial cells and keratinizing stratified squamous epithelial cells, with sharp transition boundary (arrow) between the two types of epithelial cells (HE x 200). (i) Duct-like structure lined by cuboidal epithelial cells which are connected with stratified squamous epithelial cells (HE x 200).

half being lined by keratinizing stratified squamous epithelial cells (Fig. 2g). Second, tubular structures were lined by both a layer of columnar epithelial cells and keratinizing stratified squamous epithelial cells (Fig. 2h). Third, duct-like structures, which consisted of pale cuboidal epithelial cells constituting ductlike lumens of secretory glands, were connected with non-keratinizing stratified squamous epithelial cells (Fig. 2i). Other than various teratoma components described above, relatively poor capillary networks 
were present throughout the tumor. Tissues that can determine or suggest the origin of the tumor were not recognized elsewhere in the tumor. Other visceral organs did not exhibit metastatic tumor lesions or any other significant lesions.

\section{Discussion}

Teratoma of the avian species has been recognized in the ovary, testes, kidney, adrenal gland, cerebrum, spinal cord, pineal body, and eye (Hooper, 2008; Reece, 2008; Paździor et al., 2012). In the current broiler chicken, the normal appearance of every other abdominal visceral organ, and the anatomical location of the tumor, (which was closely associated with intact ovary and covered by a single layer of cuboidal epithelial cells, as seen in normal ovaries), indicated that this teratoma was most likely a primary tumor originating from the ovary. Low mitotic rate of mesenchymal stromal cells indicating slow growth of the tumor, which was recognized in a seven-week-old chicken, and the absence of metastasis and invasion suggested this ovarian teratoma to be a benign and congenital one.

Ovarian teratoma, which has been reported previously in domestic animal species, such as the bitch, cat, sow, mare, and cow, may generally contain mature rather than undifferentiated somatic tissues (Basaraba et al., 1998; MacLachlan and Kennedy, 2002; Lefebvre et al., 2005; Schlafer and Miller, 2007). Likewise, tissue types of ovarian teratoma reported previously in the avian species may usually display well-differentiated adult morphology, even if they vary from teratoma to teratoma. In this species, teratoma tissues consist of keratinized epitheliumlined sac containing feathers, epithelial pearls formed by squamous epithelium, bone, cartilage, smooth muscle, nerve, fat, trachea, or melanocytes (Reece and Lister, 1993; Bolte and Burkhardt, 2000; Reece, 2008), and individual teratoma component shows a built-in mature anatomical feature characteristic of each somatic tissue, which can be easily identified as such. Ovarian teratoma described in the current chicken was composed of not only a variety of well-differentiated mature tissue components of mesodermal and ectodermal origin, but also multiple aberrant and heterogeneous components, particularly a variety of glandular, cystic, duct-like, and tubular structures. These heterogeneous teratoma components were unidentifiable as to corresponding embryological layer of origin. Some of these unusual structures exhibited a lining by a mixture of both keratinizing/ non-keratinizing stratified squamous epithelial cells and cuboidal/columnar epithelial cells, showing simultaneous differentiation of tumor cells into two different types of epithelial cells within a single teratoma component. Although ectodermal origin was suggested by the presence of partial lining by squamous epithelium (Berman, 2009), this notion could not be established because of the participation of cuboidal/ columnar epithelial lining. All such epithelial-lined structures did not exhibit cytologically malignant features, namely anisokaryosis, anisocytosis, and frequent mitotic figures, and therefore were regarded as mature rather than anaplastic teratoma components. In the present ovarian teratoma, histological features of those aberrant teratoma components, which were lined by a combination of two different types of epithelial cells (keratinizing/non-keratinizing stratified squamous epithelial cells and cuboidal/ columnar epithelial cells) were reminiscent of those in transdifferentiation, dedifferentiation, or simple squamous metaplasia. The phenomenon of transdifferentiation is suggested to have played a role in sacrococcygeal teratoma in human beings (JurićLekić et al., 1993). Identification of dedifferentiation is documented in an ovarian teratoma (Yasunaga et al., 2011) and other teratomas involving internal visceral organs or tissues in human beings (Game et al., 2001; Kim et al., 2012). Although ovarian carcinoma associated with squamous metaplasia is described in the bovine species (McEntee, 1990) and human beings (Kay, 1961), and even if the stratified squamous epithelium is commonly seen in ovarian teratoma, there are no reports of ovarian teratoma displaying features of ongoing squamous metaplasia in either the medical or veterinary literature. In this chicken's ovarian teratoma, the epithelia-lined structures did not show any changes associated with metaplasia. Therefore, it was not possible to accurately determine which event (transdifferentiation, dedifferentiation, or squamous metaplasia) was implicated in the development of the aberrant teratoma components during tumorigenesis.

Even if the pluripotential cell lineage can differentiate to produce a variety of somatic tissues, it seems unusual that ovarian teratoma of the broiler chicken described in this report exhibited so many morphologically diverse tissue elements. In conclusion, it may be thought that such a highly heterogeneous variant of ovarian teratoma might have indicated a curious morphological aspect of the pluripotential germ cells during tumorigenesis. This morphological expression would be largely attributable to intrinsic character of the pluripotential germ cell lineage. The present study was limited to the histopathological investigation. Thus, further cytogenetic, ultrastructural, and immunohistochemical investigations appear warranted to better understand the highly heterogeneous differentiation of tissue components in the ovarian teratoma such as that described in this report.

\section{Conflict of interest}

Author declares that he has no conflict of interest. 


\section{References}

Basaraba, R.J., Kraft, S.L., Andrews, G.A., Leipold, H.W. and Small, D. 1998. An ovarian teratoma in a cat. Vet. Pathol. 35, 141-144.

Baskin, G.B., Soike, K., Jirge, S.K. and Wolf, R.W. 1982. Ovarian teratoma in an African green monkey (Cercopithecus aethiops). Vet. Pathol. 19, 219-221.

Berman, J.J. 2009. Neoplasms: Principles of development and diversity, Sudbury, Jones and Bartlett Publishers, pp: 198-210.

Bolte, A.L. and Burkhardt, E. 2000. A teratoma in a Muscovy duck (Cairina moschata). Avian Pathol. 29, 237-239.

Campbell, J.G. and Appleby, E.C. 1966. Tumours in young chickens bred for rapid body growth (broiler chickens): A study of 351 cases. J. Pathol. Bacteriol. 92, 77-90.

Cullen, J.M., Newbold, J.E. and Sherman, G.J. 1991. A teratoma in a duck infected congenitally with duck hepatitis B virus. Avian Dis. 35, 638-641.

Dahl, N., Gustavson, K.H., Rune, C., Gustavsson, I. and Pettersson, U. 1990. Benign ovarian teratoma. An analysis of their cellular origin. Cancer Genet. Cytogenet. 46, 115-123.

Dehner, L.P., Norris, H.J., Garner, F.M. and Taylor, H.B. 1970. Comparative pathology of ovarian neoplasms. III. Germ cell tumours of canine, bovine, feline, rodent, and human species. J. Comp. Pathol. 80, 299-306.

Ford, S.L., Wentz, S. and Garner, M. 2006. Intracoelomic teratoma in a juvenile bald eagle (Haliaeetus leucocephalus). J. Avian Med. Surg. 20, 175-179.

Gamba, C.O., Damasceno, K.A., Rocha, Jr., S. S., Mendes, H.M., Faleiros, R.R. and Cassali, G.D. 2014. Ovarian teratoma in an equine fetus: A case report. Vet. Q. 34, 164-166.

Game, X., Houlgatte, A., Fournier, R., Duhamel, P., Baranger, B. and Khoury, S. 2001. Dedifferentiation of mature teratomas secondary to testicular cancer: Report of 2 cases. Prog. Urol.11, 73-76.

Gruys, E., van Dijk, J.E., Elsinghorst, T.A.M. and van der Gaag, I. 1976. Four canine ovarian teratomas and a nonovarian feline teratoma. Vet. Pathol. 13, 455-459.

Gupta, B.N. 1976. Teratoma in a chicken (Gallus domesticus). Avian Dis. 20, 761-768.

Helmboldt, C.F., Migaki, G., Langheinrich, J.A. and Jakowski, R.M. 1974. Teratoma in domestic fowl (Gallus gallus). Avian Dis. 18, 142-148.

Hooper, C.C. 2008. Teratoma in the cerebrum of a fantail pigeon. Avian Pathol. 37, 141-143.

Jurić-Lekić, G., Trosić, A. and Svajger, A. 1993. Lentoids within sacrococcygeal teratoma: Origin by transdifferentiation?. Hum. Pathol. 24, 227-229.

Kay, S. 1961. Carcinoma with squamous metaplasia of the ovary (so-called adenoacanthoma). Am. J.
Obestet. Gynecol. 81, 763-772.

Kim, J.Y., Lee, C.H., Park, W.Y., Kim, J.Y., Kim, A.R., Shin, N., Park, D.Y. and Huh, G.Y. 2012. Adenocarcinoma with sarcomatous dedifferentiation arising from mature cystic teratoma of the anterior mediastinum. Pathol. Res. Pract. 15, 741-745.

Kraus, F.T. 1977. Female genitalia. In Pathology, Eds., Anderson, W. A. D. and Kissane, J.M. Saint Louis, CV Mosby, pp: 1680-1775.

Kuno, N., Kadomatsu, K., Nakamura, M., MiwaFukuchi, T., Hirabayashi, N. and Ishizuka, T. 2004. Mature ovarian cystic teratoma with a highly differentiated homunculus: A case report. Birth Defects Res. A. Clin. Mol. Teratol. 70, 40-46.

Lefebvre, R., Theoret, C., Doré., M., Girard, C., Laverty, S. and Vaillancourt, D. 2005. Ovarian teratoma and endometritis in a mare. Can. Vet. J. 46, 1029-1033.

MacLachlan, N. J. and Kennedy, P. C. 2002. Tumors of the genital systems. In Tumors in domestic animals, Edt., Meuten, D. J. Ames, Iowa State Press, pp: 547-574.

McEntee, K. 1990. Ovarian neoplasms. In Reproductive pathology of domestic animals, San Diego, Academic Press, pp: 69-93.

Mohamed, Z. A., Hassan, E. I. and Salim, A.I. 2006. Malignant teratoma in a domestic fowl (Gallus gallus domesticus). Sudan. J. Vet. Res. 21, 75-80.

Outwater, E. K., Siegelman, E. S. and Hunt, J. L. 2001. Ovarian teratoma: Tumor types and imaging characteristics. Radiography 21, 475-490.

Paździor, K., Szweda, M., Otrocka-Domagala, I. and Rotkiewicz, T. 2012. Extragonadal teratoma in a domestic turkey (Meleagris gallopavo domestica). Avian Pathol. 41, 285-289.

Reece, R. L. 2008. Other tumors of unknown etiology. In Diseases of poultry, Edt., Saif, Y.M, Ames, Blackwell, pp: 593-616.

Reece, R. L. and Lister, S. A. 1993. An abdominal teratoma in a domestic goose (Anseriformes, Anser anser domesticus). Avian Pathol. 22, 193-196.

Rodríguez, J. L., de las Mulas, J. M. and de los Monteros, A. E. 1994. Ovarian teratoma in a ferret (Mustela putorius furo): A morphological and immunohistochemical study. J. Zoo Wildlife Med. 25, 294-299.

Sato, T., Hontake, S., Shibuya, H., Shirai, W. and Yamaguchi, T. 2003. A solid mature teratoma of a feline ovary. J. Feline Med. Surg. 5, 349-351.

Schanmughapriya, S., Senthilkurnar, G., Balakrishnan, K., Vasanthi, N., Vinodhini, K. and Natarajaseenivasan, K. 2011. Bilateral ovarian teratoma complicated with carcinosarcoma in a 68 year old woman: A case report. BMC Cancer 11, 218-220.

Schlafer, D. H. and Miller, R. B. 2007. Neoplastic diseases of the ovary. In Maxie MG (ed) Jubb, 
Kennedy, and Palmer's pathology of domestic animals. Edt., Maxie, M. G. Edinburgh, Elsevier Saunders, pp: 450-456.

Tsubota, K., Yoshizawa, K., Fujihira, S., Okazaki, Y., Matsumoto, M., Nakatsuji, S. and Oishi, Y. 2004. A spontaneous ovarian immature teratoma in a juvenile rat. J. Toxicol. Pathol. 17, 211-218.

Yasunaga, M., Saito, T., Eto, T., Okadome, M., Ariyoshi, K., Nishiyama, K. and Oda, Y. 2011. Dedifferentiated chondrosarcoma in a mature cystic teratoma of the ovary: A case report and review of the literature. Int. Gynecol. Pathol. 30, 391-394. 